\title{
VAQUEJADAS CONTEMPORÂNEAS: festa, cultura e negócio
}

\section{CONTEMPORARY VAQUEJADAS: party, culture and business}

\author{
Janio Filgueira Aires \\ Luiz Assunção
}

\section{Resumo}

O presente artigo objetiva, de forma geral, analisar como a vaquejada-espetáculo influencia a constituição da cultura do negócio e da festa, caracterizando formas de ser vaqueiro e patrão, construindo dinâmicas sociais diversas nas relações estabelecidas entre patrões, vaqueiros e frequentadores do evento. O estudo tem por base trabalho de campo realizado em vaquejadas de diferentes cidades do Rio Grande do Norte, em particular, no Porcino Park Center da cidade de Mossoró-RN.

Palavras-Chave: Vaquejada. Negócio. Festa. Espetáculo.

\begin{abstract}
This article aims to analyze, in a general way, how the vaquejada-spectacle influences the constitution of the business and party culture, characterizing ways of being a cowboy and boss, building diverse social dynamics in the relationships established between bosses, cowboys and attendees of the event. The study is based on fieldwork conducted in vaquejadas of different cities of Rio Grande do Norte, in particular, in the Porcino Park Center of the city of Mossoró-RN.
\end{abstract}

Keywords: Vaquejada. Business. Party. Spectacle.

\section{Introdução}

Este artigo tem como foco central pensar a vaquejada ${ }^{1}$ imbuída da festa, da cultura e do negócio na contemporaneidade. Partimos da premissa de que a vaquejada-espetáculo se produz, simultaneamente, pela cultura, apropriada pelo consumo e do consumo apropriado pela cultura. Assim, ao mesmo em tempo que o consumo irrefletido no evento dos vaqueiros e patrões se torna um ato socialmente regulado, a vaquejada e seus derivados se constituem em mercadorias reinventadas pelo negócio com a intenção de ganhar dinheiro. Nesse sentido, a vaquejadaespetáculo, condicionada pelas conquistas de prêmios e pelo negócio, intensificaria as trocas materiais e simbólicas, configurando efeitos diversos ao status social do vaqueiro e do patrão,

\footnotetext{
* Doutorando no Programa de Pós-Graduação em Ciências Sociais (UFRN). Professor na Universidade Potiguar (Mossoró, RN). E-mail: janiofilgueira@homail.com.

${ }^{* *}$ Professor titular do Departamento de Antropologia da Universidade Federal do Rio Grande do Norte (UFRN). E-mail: lassuncao@ufrnet.br.

1 A vaquejada é um evento esportivo e festivo revelado por práticas diversas dos seus atores sociais. A atividade esportiva se constitui de corrida numa pista de competição seguida da puxada do boi pelo rabo. Por sua vez, as festas são realizadas, simultaneamente, junto com as competições nas pistas de corrida dos parques de vaquejada, nos clubes e nos espaços dos caminhões. Na contemporaneidade, a vaquejada se enquadra pelo estilo de vida urbano e rural, como por adoção de referência histórica e cultural do poder de mando, nas quais os patrões expressam sua "força simbólica" sobre os vaqueiros, frequentadores e sociedade.
} 
como também, provocando prestígios diferenciados aos participantes dessas competições, mas não atingindo mudanças na hierarquia. Os vencedores são intitulados de patrões e vaqueiros fortes e os perdedores são referenciados de patrões e vaqueiros fracos. No entanto, por mais que patrão e vaqueiro sejam vencedores, a divisão hierárquica entre eles permanece no tempo, uma vez que a referência àquele como superior, provedor, patrocinador e investidor, e deste como inferior e empregado, continuou histórica e culturalmente se reproduzindo também na vaquejada-espetáculo.

Essas práticas, nestes eventos, não ocorrem apenas no Nordeste no sentido singular, mas em grande parte do Brasil, como Rio de Janeiro, Minas Gerais, Goiás, Mato Grosso, Mato Grosso do Sul, Amazonas, dentre outros estados da federação brasileira. Há sim vaquejadas no sentido plural, tendo em vista que existe uma diversidade de competições, práticas e praticantes que permite entender as múltiplas facetas regionais, inter-regionais, culturais, sociais, identitárias e relacionais, configuradas pelas relações de poder e as relações de gênero. Diante desta diversidade, o presente estudo objetiva, de forma geral, analisar como a vaquejada-espetáculo influencia a constituição da cultura, do negócio e da festa.

$\mathrm{Na}$ vaquejada, o termo "negócio" se refere ao espaço comercial e ao ato de compra, troca, venda e lucro, mas também como valor simbólico que constitui e legitima as posições que os personagens ocupam no contexto social do evento. Tal perspectiva influencia o modo de constituir a vaquejada, vaqueiros, patrões e frequentadores. Desse modo, a vaquejada deixa de ser uma brincadeira do passado sem fins lucrativos para ser um campo de negócios em que há investimento em vaqueiros, cavalos e eventos de entretenimento para conseguir angariar recursos financeiros ${ }^{2}$.

Entendemos, nessa pesquisa, que na competição e na festa há a invenção de um mundo econômico e não econômico, material e imaterial, fomentando o espetáculo e o negócio na vaquejada ${ }^{3}$, através de referências simbólicas e econômicas na constituição das relações entre patrões e vaqueiros. Assim, há um processo dialético na espetacularização que envolve coisas, seres humanos e contextos imersos que produzem sentido para a sua existência com perspectivas econômicas e não econômicas articuladas com a percepção de sua função ideológica e política, produzindo uma ordem arbitrária estruturante do sistema de dominação vigente (BOURDIEU, 1996).

A pesquisa foi realizada durante três anos (2015 a 2017), tendo por campo as vaquejadas de Currais Novos, Caicó e Mossoró. Por um período mais sistemático, optamos por acompanhar

\footnotetext{
2 Vale lembrar que o espetáculo e o negócio já foram tratados em pesquisas recentes sobre a vaquejada, embora sem buscar entender especificamente as relações entre patrões e vaqueiros. Dentre as pesquisas se podem elencar: Aires, 2008; Barbosa, 2006; e Silva, 2013.

3 O espetáculo é visto por Carvalho (2010), Debord (1997), Adorno e Horkheimer (1947) centrado na indústria cultural de massas e da tecnologia, descaracterizando a cultura popular e os sujeitos da sua comunidade de origem. Desse modo, a descontinuidade histórica e cultural permite, apenas, reconstituir o presente com os retalhos ou sem o passado para fomentar a história, a cultura e a economia da vaquejada.
} 
a de Mossoró, mais especificamente as diversas atividades ocorridas no Porcino Park Center. A escolha de Mossoró deu-se por ser atualmente a principal cidade promotora da vaquejada no estado do Rio Grande do Norte. Nela são realizadas vaquejadas em pequenos circuitos todo fim de semana, bem como executa duas vezes por ano, em abril e outubro, vaquejadas-espetáculo no Porcino Park Center.

A proposta metodológica foi norteada pela etnografia com a utilização dos recursos da observação direta, entrevistas abertas, relatos de conversas com vaqueiros e patrões. No campo, além do acompanhamento permanente das diferentes atividades que envolviam os vaqueiros, procuramos estabelecer um diálogo (CLIFFORD, 1998) permanente com os diversos interlocutores, incorporando as múltiplas vozes, mas também os gestos, falas, silêncios, que possam propiciar o entendimento das diversas questões, os detalhes, as diferenças, as similaridades e os conflitos presentes na vaquejada e entre seus participantes.

\section{Porcino Park Center: uma cidade itinerante}

A pesquisa realizada nos parques de vaquejada do Rio Grande do Norte, em especial, Mossoró, Caicó e Currais Novos conduziu a que se viesse a associar esses contextos à imagem de uma cidade itinerante.

A explicação para isto advém do fato de a cidade não ser configurada apenas de espaços físicos, mas de lugares recheados de relações sociais. Assim, "a cidade, mais do que um mero cenário onde transcorre a ação social, é o resultado das práticas, intervenções e modificações impostas pelos mais diferentes atores em sua complexa rede de interações, trocas e conflitos" (MAGNANI, 2009, p.132). Seu universo é composto de redes de interações sociais, trocas e conflitos, o que evidencia e demonstra a sua dinamicidade na constituição do ser social. Os parques de vaquejada terminam sendo espaços diversificados, do modo de ser vaqueiro e patrão, tanto pelos deslocamentos constantes destes, em torno dos seus grupos de amigos e de seus concorrentes, dos componentes das competições e de populares, quanto das mudanças frequentes para as cidades e da profusão de eventos programados durante as competições.

De acordo com Barbosa (2006, p. 92), o evento pode ser pensado como uma pequena cidade, em razão de ser "caracterizado por práticas sociais bastante distintas, que nos permite perceber o parque como se fosse uma 'cidade', dividida entre a zona residencial e a zona central'. Essa concepção de cidade, por parte deste autor, é construída a partir das práticas sociais diferentes realizadas nos parques, bem como do sentido atribuído às organizações espaciais dos caminhões dos vaqueiros. Tais espaços são considerados como casas e as outras partes da estrutura do parque de vaquejada, como a pista de competição, os clubes para festa, o comércio, dentre outros, são vistas como espaço público da rua. Esta associação espacial ao universo social é também abordada por Da Matta (1997), nos seus estudos sobre o modo como o público e o privado são praticados no Brasil. 
Quando digo então que "casa" e "rua" são categorias sociológicas para os brasileiros, estou afirmando que, entre nós, estas palavras não designam simplesmente espaços geográficos ou coisas físicas comensuráveis, mas acima de tudo entidades morais, esferas de ação social, províncias éticas dotadas de positividade, domínios culturais institucionalizados (DAMATTA, 1997, p. 15).

Partindo-se desse princípio, vê-se que as associações ao espaço não se referem apenas a construções geográficas, mas também sociais, resultantes da presença de valores e ideias culturais institucionalizadas pelas relações sociais.

O espaço da vaquejada do Porcino, composto da chamada casa e da rua, revela sociabilizações diferenciadas entre os seus personagens, que configuram expressões distintas da noção de vaqueiro e de patrão. No primeiro, observa-se a casa, configurada pelos caminhões dos vaqueiros, localizados tanto por trás do brete (ou currais por onde o boi entra na pista), como no terreno que se situa do outro lado do lago. A casa, nesse aspecto, pode ser entendida como um espaço reservado aos vaqueiros que permite o encontro de amigos, de familiares e da organização do seu cotidiano durante as competições.

No segundo, situa-se o espaço da rua, baseado na parte exterior do parque, assim como no seu interior, constituído por cinco bares, a pista de competição e o corredor, que se apresenta entre a pista de competição e o clube que promove festas durante os três dias da vaquejada. É o local que permite o encontro mais abrangente entre os diversos competidores, patrões e populares, tornando-se um espaço estratégico para se consolidar a afirmação social dos vaqueiros. Isso porque, nesse espaço, existe a oportunidade de serem vistos e aprovados socialmente, uma vez que todos os personagens da vaquejada estão acompanhando a sua apresentação na pista de competição. Os vaqueiros podem explorar essa visibilidade fazendo apresentações, puxando, correndo, passeando ou corrigindo o seu cavalo. E mais: podem também explorar a congregação dos variados atores sociais na vaquejada para construir amizades, consumir bebidas alcoólicas, brincar, conversar e se divertir. Todos esses aspectos são maneiras de praticar relações sociais que exprimem encontros com o universo da masculinidade, do ser macho, do ser vaqueiro e patrão.

Observando a partir da lógica da casa e da rua (DAMATTA, 1997), entende-se que a vaquejada se revela, através de um ambiente dinâmico no qual um espaço pode ser imbricado no outro, quando os atores se veem envolvidos por meio de situações sociais específicas. Na rua, por exemplo, determinados vaqueiros e patrões podem se relacionar como amigos e compadres. Já na casa, em determinadas circunstâncias, a impessoalidade pode se apresentar entre os vaqueiros, patrões e entre os membros da sua equipe, quando estes negociam cavalos e analisam o momento da corrida na competição. Todavia, nesses espaços, há em geral uma tendência para a pessoalidade, no que diz respeito à casa, e para a impessoalidade, no caso da rua. A casa e a rua na vaquejada são constituídas provisoriamente durante a realização do evento. Chegando ao parque, os vaqueiros estendem uma espécie de tenda, ou toldo, que se conecta do caminhão ao chão por meio de barras de ferro. Assim, se constitui a residência provisória desses personagens, 
a qual serve de local para o seu repouso, sua própria alimentação e a dos cavalos e a sociabilização dos vaqueiros.

Os caminhões são enfileirados no parque de um lado e do outro, no sentido de formar caminhos entre eles, como se fossem várias ruas de um pequeno bairro de cidade. Essas ruas são fundamentais para o trânsito de carros e de populares que vêm para o evento ou que simplesmente se deslocam até os caminhões dos vaqueiros. No Parque Porcino, o movimento é tão intenso e tamanha é a quantidade de carros, que se costuma deslocar um guia para orientar o trânsito e o estacionamento dos veículos, organizando-os a partir das ruas principais conectadas à arena de competição.

Os caminhões (a casa dos vaqueiros e patrões) que chegam para competição, geralmente, situam-se por trás e do lado da pista de competição. Especificamente em relação à casa, ela é desenvolvida nos carros conhecidos como caminhões de estilo gaiola ou trailer.

Foto 01: Caminhão dos vaqueiros e patrões, em estilo trailer.

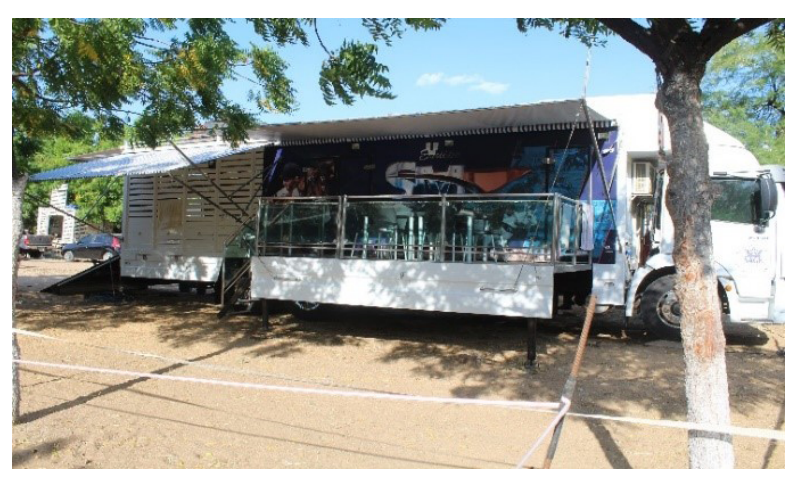

Fonte: Acervo particular de Francisco Janio Filgueira Aires, 2017.

Foto 02: Caminhões dos vaqueiros e patrões, em estilo gaiola.

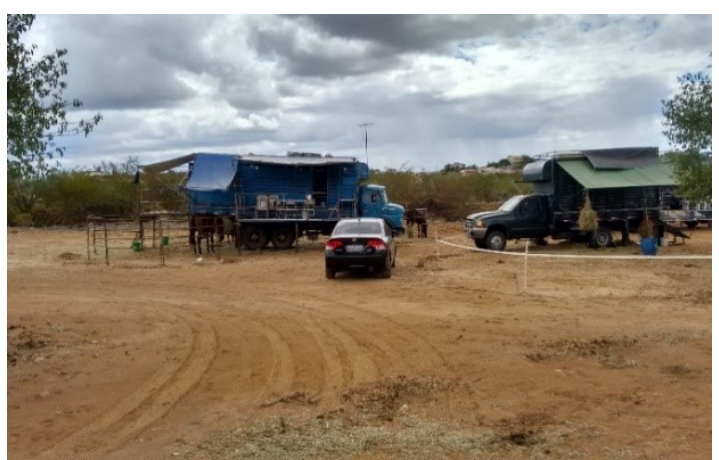

Fonte: Acervo particular de Francisco Janio Filgueira Aires, 2017. 
Ambos os tipos são constituídos de compartimentos, dos quais uma parte é destinada para ser a cozinha e outra, para os cavalos. Nesses caminhões, foram observados formatos diferenciados segundo a condição social de cada vaqueiro ou de cada patrão que investe financeiramente para ter o vaqueiro competindo nas vaquejadas. Sendo assim, o modelo de estada nos caminhões fica condicionado ao tamanho do investimento financeiro realizado para o conforto dos seus membros. Há aqueles que investem mais e menos no conforto e na comodidade dos seus vaqueiros. Assim, os caminhões oferecem diferentes estilos de conforto. Contudo, esse espaço é utilizado não apenas para descansar e alimentar os vaqueiros, mas também para recepcionar os familiares e companheiros das vaquejadas nos seus caminhões. Por isso, é reservado a amigos e familiares, constituindo assim um espaço privado que se desenvolve por meio de relações, sobretudo de afinidade. Nos caminhões é muito comum se reunir para conversar e para fazer festas com vaqueiros, pessoas da família, amigos e mulheres que são "conquistadas" (termo usado pelos vaqueiros) durante o evento. As festas são produzidas com a ingestão de cachaça, de uísque, de refrigerantes, junto com carne de boi, de bode, com farofa, arroz e feijão.

A atuação dos diferentes personagens da vaquejada, em vários setores do parque, dáse graças à estrutura em torno da pista de competição, que é preparada para atender ao ritmo frenético da vaquejada, mediante a instalação de vários tipos de comércios e de meios para diversão, como as festas no clube, nos espaços dos bares e nos próprios caminhões dos vaqueiros, provocando deslocamentos significativos desses atores, constituindo momentos de interações sociais na vaquejada.

\section{O estilo de vida e da festa na vaquejada}

Quando se fala em sociedade, pensa-se em formas de viver e de existir que dão sentido à vida de uma comunidade. Na vaquejada não ocorre diferente. Há estilos de ser e de viver que se conectam à sociedade, bem como há particularidades que são executadas cotidianamente em seus eventos. Na vaquejada promove-se estilos de vida que se configuram pela maneira como atuam e representam o mundo no evento, a saber: o tipo de vestimenta, o cavalo, as brincadeiras e as festas.

As vestimentas nas vaquejadas são compostas de acessórios que diferem desta paisagística comum, embora seja comum às pessoas usarem bonés, calças jeans e camisetas em seu cotidiano. As botas de couro, as perneiras, os chicotes dos vaqueiros e dos patrões são instrumentos que demarcam referências para dizer quem é quem na vaquejada. Embora sejam aparentemente semelhantes, as vestimentas conferem valor social distinto aos vaqueiros e patrões pelas marcas estampadas nas suas vestimentas, a saber: Lacoste, Polo Play, Ralph Lauren, Colcci, dentre outras. As classes sociais nas vaquejadas são identificadas pelas vestimentas de cada um. Vestir bem não demonstra, apenas, uma aparência física, mas também significa implicitamente alguém que tem posses financeiras elevadas (no campo da pesquisa, semelhante ao patrão). 
Nas competições notam-se diferenças mais acentuadas entre patrão e vaqueiro pelo uso das vestimentas de marca, da expressão corporal e pelo estado das roupas que ficam sujas, amassadas e suadas. Nessa condição, conforme apontam os vaqueiros, se pode reconhecer quem é o patrão, o vaqueiro e o frequentador na competição. Os vaqueiros advindos da competição se encontram "sujos e suados", enquanto que o patrão se encontra, quase sempre, "limpo e engomado". E o frequentador que assiste à vaquejada, dependendo da sua condição financeira, pode se enquadrar, tanto no primeiro estilo, quanto no segundo.

Além da estética da vestimenta, há o ato performático na aprovação ou desaprovação do vaqueiro e do patrão na vaquejada. É na expressão do movimento corporal cavalo/homem/boi que a obra performática simboliza o ser vaqueiro, o ser patrão, ser cavalo e boi na competição. Referindo-se ao ato performático, Paul Zumthor (2010, p. 166) destaca que o mesmo "implica competência. Além de um saber-fazer e de um saber dizer, a performance manifesta um saberser no tempo e espaço [...] que é emanada no corpo".

A performance uníssona na qual vaqueiro e cavalo aparecem na sua técnica como se fossem um só consegue da plateia e do patrão palmas, gritos, falas e gestos de satisfação pela derrubada certeira do boi. Essas performances positivas nas competições levam vaqueiros a constituir uma imagem própria para fazer um marketing de si mesmo. Uns utilizam da tradição familiar, mostrando que já tiveram campeões em sua família e que hoje têm esta continuidade com seu ente competindo. Outros utilizam sua posição social, quando o locutor enfatiza que este competidor é do grupo empresarial tal. Outros dão nome a sua performance na corrida e derrubada do boi, como performance exclusiva que ele sabe fazer com arte e maestria. Isso foi constatado quando um vaqueiro do Pará, Nathan Queiroz, competindo na vaquejada executou a manobra "Capa Loka", denominada pelos vaqueiros e popularizada por ele, "com o cavalo mansinho e prancha”.

A denominação "mansinho" se refere ao cavalo manso, que obedece fielmente às coordenadas do vaqueiro. O termo "prancha" significa a manobra que o vaqueiro faz usando o cavalo como prancha se deslocando para o lado inverso do seu animal. A partir da repercussão da técnica utilizada nas vaquejadas, o vaqueiro laçou, em 2016, na cidade de Mossoró, sua grife "Capa Loka", composta por camisas, música ${ }^{4}$, bonés e peitoral para cavalos. A estratégia adotada pelo vaqueiro - adentrar no universo do comércio - pode vir a gerar lucros, como ganhar dividendos com o sucesso da empreitada e, consequentemente, possibilitar sua condução ao patronato, posição que poucos vaqueiros conseguem alcançar.

Por outro lado, quando não há a performance esperada, a plateia e o patrão externam discursos negativos (é comum falar em voz alta que o boi é ruim; que o vaqueiro não é bom) e expressões corporais (franzem a testa, batem na mesa, mexem o chicote que tem na mão, mexem no celular, ingerem rapidamente o que tiver próximo dele, cachaça, água, refrigerante, alimento) que podem denotar, desconfiança e insatisfação ao seu competidor.

4 Para conhecer a música Estilo Capa Louca, acessar o link: https://www.letras.mus.br/pedrinho-pegacao/capa-louca/. 
Além da competição há outros espaços em que é possível observar diferentes expressões do estilo de vida dos vaqueiros e dos patrões na vaquejada, como os comportamentos no cotidiano do parque e da festa, presentes no imaginário musical.

As práticas de entretenimento ${ }^{5}$ são executadas pelo passear a cavalo, realizar festas nos caminhões e no parque, consumir alimentos, ingerir álcool, produtos da vaquejada, como realizar brincadeiras jocosas e feminilizantes. Dessa forma, os frequentadores, os vaqueiros e os patrões se "vaqueirizam", conforme Barbosa (2006), assim como, parafraseando este autor, se patronizam ${ }^{7}$.

A jocosidade ${ }^{8}$ é uma das práticas que se vaqueirizam e se patronizam. A distinção desse comportamento depende do tipo e do sentido da ação dos sujeitos. Na vaquejada do Porcino foi possível observar um grupo de vaqueiros e patrões reunidos assistindo à competição e após uma puxada errada do boi por um vaqueiro do dono daquele parque, fez um patrão que assistia ao evento enfatizar: "fulano, esse seu cavalo não presta para nada. Ele tá com espinha dura demais por isso não bota boi. Ah! Ah! Ah! Agora veja o que é cavalo bom que vem aí, como o meu, meu patrão?" Aos risos todos que estavam com aquele patrão riram no sentido de provocação ao outro vaqueiro e patrão.

A jocosidade diante da presença do patrão conduz mais ainda à obrigação de que o vaqueiro deve demonstrar seu valor diferenciado em relação aos outros vaqueiros. Essa busca pela comprovação é tão comum na vaquejada que o termo empregado, tanto pelos vaqueiros e patrões, como pelos frequentadores, "é testado e aprovado", inclusive a imprensa que faz a cobertura do evento também usa essa terminologia para fazer comercial de produtos. Nesse sentido, provar que é bom não se revela apenas na conquista de prêmios, configura também valores que dão qualidade ao produto e ao produtor de um bem ou de um vaqueiro patrocinado por um patrão.

A jocosidade vai ao extremo ao demonstrar seu poder. Ao se aproximar para conversar com um patrão para entrevistar, destacou: "rapaz só faço após pagar e tomar várias cervejas. Certo? Menino compre cervejas para gente!". Outro patrão disse: “Só estou na vaquejada por esporte mesmo, para brincar e encontrar os amigos". Nesse sentido, há um desejo de revelar seu poder de mando, para que as pessoas reconheçam sua "força financeira," esbanjando sua influência no contexto da vaquejada e da sociedade.

5 Os "alpendres" dos seus caminhões, assim como os bares, as festas, as arquibancadas e as ruas do parque, funcionam como um dos pontos referenciais para estes encontros e reencontros jocosos e feminilizantes com os vaqueiros, frequentadores e patrões. Neles se propagam estilos de ser vaqueiros e patrões.

6 "Vaqueirizar" nas vaquejadas-espetáculos são práticas reguladas socialmente nas quais os sujeitos atribuem códigos simbólicos e práticas comuns para reproduzir um tipo de ser vaqueiro na vaquejada.

7 Patronizar é a todo custo exaltar o dono e a "alma para o negócio" da vaquejada, que são as práticas semelhantes do patrão. Por isso os vaqueiros e os frequentadores tendem a reproduzir os valores difundidos na vaquejada pelos patrões, a saber: "ser responsável, zeloso, homem de palavra, tratar o outro com cordialidade e autoridade de patrão".

8 Entendo jocosidade como ato recíproco de brincar com o outro sem utilizar esta prática como uma ofensa. 
Provar ser bom na vaquejada é também coisa de macho, remetido ao vaqueiro e ao patrão pela busca do referencial ideal da masculinidade hegemônica, face às masculinidades alternativas ou subalternas, que deve ser alcançado e almejado por todos. Referindo-se de modo semelhante ao processo social em construção, Fátima Cecchetto (2004, p. 67) afirma que "para entender os diferentes tipos de demanda das masculinidades, é fundamental o exame das práticas na qual a hegemonia é constituída". Seguimos a afirmação em determinados momentos do trabalho de campo ao observar, durante as competições nas vaquejadas, os sentidos atribuídos à condição do vaqueiro, como "macho", a partir das disputas jocosas e da feminização. Tais disputas foram reveladas quando um vaqueiro tomou a palavra e exclamou "existe os machos, mas existe as bichinhas, como esse aí. "Ei, você é fraco; ontem fiquei com várias mulheres e você não ficou com nenhuma”. O outro repudiou: deixe de onda cara”. Estes discursos remetem à perspectiva de tentar ser mais vaqueiro e mais macho do que o outro, sobretudo, quando se está diante do patrão. Nesse aspecto, buscar ser mais macho do que o outro diante do patrão é tentar demonstrar que é mais preparado, determinado e mais vaqueiro.

No que remete às festas, o discurso se enaltece pela representação do dinheiro e do consumo como passaporte para todas as outras possiblidades, inclusive para conquistar mulheres, admiração e respeito das pessoas. Essa lógica se apresenta em todos os espaços sociais. Quando uma determinada música retrata o encontro do patrão com a fazenda, o cantor enaltece pela mesma ótica do dinheiro e do consumo. Assim, o patrão que tem uma vida urbana, ao se deslocar para fazenda se torna um playboy fazendeiro. É o que se observa na música Playboy Fazendeiro do cantor Mano Walter.

\section{Mano Walter, Playboy Fazendeiro}

Tenho muito gado no pasto e o bolso cheio de dinheiro. Quem foi que chegou? O playboy fazendeiro! Olha que eu tenho uma Hilux. Uma Amarok e uma Pajero Quem foi que chegou? O playboy fazendeiro! Olha que eu moro na cidade. Mas no fim de semana vou pra minha fazenda fazer aquela farra. Convido a mulherada, só do tipo Panicat. Vai rolar uísque e cerveja bem gelada. Paredão ligado, as minas descem até embaixo. Mandei matar um boi pra fazer aquele churrasco. Aqui é só sossego, é só tranquilidade.[...] (WALTER, 2016).

"Playboy fazendeiro" se constitui, nessa musicalidade, assim como na vaquejada, um patrão com estilo de vida urbano, associado a uma vida social intensa, recheado de consumo, ostentação financeira e com a fama de conquistador de mulheres. O playboy sendo um fazendeiro da cidade tem seu roteiro de vida que difere muito da vida cotidiana da fazenda ${ }^{9}$, como era proposto no passado. Assim, a vaquejada imbuída da ideia da fazenda é uma maneira de projetar o universo urbano, reverberando para o desejo de ser vaqueiro e patrão.

9 Patrão da fazenda era aquele que vivia do universo agrário e tinha o comportamento tradicional como marca das suas relações sociais, a saber: o cunhadismo, o compadrio e a braveza como honra. 
Já foi visto que o universo do patrão é norteado pelo estilo urbano do dinheiro e do consumo, mas como a musicalidade trata o vaqueiro? Segue o princípio idêntico ao do patrão, a saber: dinheiro, ostentação, consumo e conquista de mulheres. A música balada do vaqueiro retrata essa representação:

\begin{abstract}
Mano Walter. Balada do Vaqueiro
E da vaquejada prum bar, do bar para o motel. E na boiada eu sou carrasco, na cama eu sou cruel. Whisky, Red Bull, e o bolso cheio de dinheiro. Galera fica doida na balada do vaqueiro. Mandei lavar meu carro, regulei meu paredão. Separei meus cavalos, quarto de milha, alazão. Peguei a minha cela, espora, luva e chicote. Coloquei os cavalos lá encima do reboque. Já comprei a bebida, convidei a mulherada. Chegou o fim de semana eu vou partir pra vaquejada (WALTER, 2016).
\end{abstract}

Esse discurso apresenta também a diferença entre o patrão playboy e o vaqueiro boy, pela superioridade na ostentação financeira do primeiro sobre o segundo. Assim, o que vale aqui é a regra, "quem tem mais pode mais", pelo menos é o que norteia a concepção dos vaqueiros. Logo, o patrão playboy se reveste de um status maior. Ao mesmo tempo, a balada do vaqueiro sinaliza para todos que vão à vaquejada, um estilo de vida comum, baseado no consumismo, como ingestão de bebida alcoólica, de custo financeiro elevado. A música, ao fazer analogia ao ser vencedor na competição, demonstra que ganhar na vaquejada sinaliza fama, status social e mulheres.

A "Balada do vaqueiro" reflete a vaquejada, não como objeto da alienação e do simples lucro, como abordou Silva (2013), mas a partir da ideia de que, ao mesmo tempo em que é consumida é reinventada (BARBOSA, 2006), regulada por relações sociais presentes no contexto da sociedade. A vaquejada e seus figurantes seguem práticas, valores e normas institucionalizadas pelo modo de vida vigente da sociedade. Desse modo, "são as práticas institucionais e sociais que condicionam todo comportamento individual, mesmo aquele que tem a ver com mudança, e não apenas com a mera reprodução do mundo", conforme Souza (2009, p.94).

Ao sinalizar práticas sociais significativas, comuns a grande parte dos frequentadores do parque de vaquejada, que acreditam viver um modelo que inclui formas de como beber, exibir roupas e carros de luxo, formas de diversão e lazer, a "balada do vaqueiro" elabora uma representação de um determinado modelo de sociedade em que o consumo é o expoente máximo desse processo na sociedade contemporânea.

A musicalidade traduz, além da premiação em dinheiro, o sentimento de esportividade, de alegria e de coroação de suas conquistas. É o que pode ser visto na música "Vou pra vaquejada", da banda Solteirões do Forró.

\title{
Solteirões do Forró. Vou Pra Vaquejada
}

Eu vou para a vaquejada e vou levar você, pra ver o gado cair e meu cavalo correr. $\mathrm{Na}$ vaquejada sempre é do vaqueiro, o boi é do vaqueiro e a gente adora, dança e se diverte com a mulherada, se acaba a vaquejada o nordeste chora. Mulher bunita troca de 
batom para ver o vaqueiro fazer tirar sua senha, sou vaqueiro classificado, ei ô mulher de gado venha dançar comigo venha. Eu vou pegar na cauda e puxar meu bate esteira, no meio da faixa vou botar o boi no chão, vou ouvir o juiz gritando valeu boi, e o povo confirmando que eu sou campeão. [...] (SOLTEIRÕES DO FORRÓ, 2017).

A música retrata o vaqueiro como um obstinado a derrubar boi para ser campeão e, com isso, adquirir todas as recompensas dessa conquista. O prazer de derrubar boi se associa à conquista de prêmios e ao desejo de esbanjar sua performance vitoriosa com mulheres. Contudo, fazer referência ao vaqueiro como um apaixonado pela vaquejada e por mulheres não configura a ideia de que existem apenas duas identidades de gênero, masculino e feminino, no evento. A vaquejada e a própria sociedade são compostas por masculinidades hegemônicas sobre as identidades de gênero, conhecidas como subordinadas, alternativas ou à margem, a saber: femininas e homossexuais. As primeiras têm destaque por serem vistas como as mais adequadas ao modelo de sociedade (e da vaquejada) vigente. As segundas se revelam nos universos ocultos, sobretudo na vaquejada, para não tornar o evento desqualificado aos olhares do patriarcalismo e do ser macho.

\section{As relações estabelecidas entre patrões e vaqueiros, profissionais e amadores, na vaquejada contemporânea}

O presente tópico objetiva analisar as relações estabelecidas entre patrões e vaqueiros. Para auxiliar nesta reflexão, utilizo a ideia de campo social e habitus, ancorada por Bourdieu (2011), bem como, a filosofia do dinheiro, preconizada por Simmel (1907), como fio condutor principal, para a explicação dos significados entre tais sujeitos da vaquejada.

Parto da ideia de que a troca material e simbólica presente entre patrões e vaqueiros é configurada pelo campo social, pelo habitus e pelo acúmulo do capital simbólico, em conformidade com o que salienta Bourdieu (2011). O campo social representa o campo simbólico, onde os confrontos legitimam as representações. Já o habitus é a capacidade dos sentimentos, pensamentos e ações dos indivíduos, de incorporar as estruturais sociais. E, por fim, o capital é o acúmulo de forças que o indivíduo pode alcançar no campo.

\footnotetext{
A estrutura do campo é um estado da relação de força entre os agentes ou as instituições engajadas na luta ou, se preferirmos, da distribuição do capital específico que, acumulado no curso das lutas anteriores, orienta as estratégias ulteriores. Esta estrutura, que está na origem das estratégias destinadas a transformá-la, também está sempre em jogo. (BOURDIEU, 2011, p. 90)
}

Bourdieu (2011) não separa o campo social do habitus, que permite a constituição das relações de forças. O espaço social é um espaço não físico, em que posições distintas estão dispostas. As posições sociais de um mesmo espaço social estão sob um mesmo parâmetro de 
regras e se relacionam umas com as outras, a partir dos diferentes capitais acumulados (como capital econômico, as riquezas; capital cultural, o acúmulo da cultura legítima; ou capital social, o pertencimento a uns grupos sociais, uma família distinta).

$\mathrm{Na}$ vaquejada-espetáculo este campo se produz através das relações estabelecidas entre os vaqueiros profissionais, patrões e vaqueiros amadores. $\mathrm{O}$ empresário e vaqueiro amador Ailson Junior enfatizou que: "estou na vaquejada porque sou apaixonado. Já deixei de comprar uma caminhonete de $\mathrm{R} \$ 150.000,00$ (Cento e cinquenta mil reais) para comprar um cavalo. $\mathrm{E}$ em seguida ele morreu, mas não me arrependo não, de ter comprado o cavalo" (JUNIOR, 2017). Assinalando na mesma perspectiva, o agricultor e o vaqueiro amador, Lucas Lima diz que: "eu corro porque gosto mesmo. É só pra matar o verme. Como eu disse, eu nem ganho. Eu gostaria de ter um patrão" (LIMA, 2017).

Os dois discursos destacam o prazer em participar da vaquejada, como prática esportiva. No entanto, o segundo associa a sua realização como vaqueiro profissional no futuro pela necessidade de se ter um patrão.

Por outro lado, diferente dos vaqueiros amadores, a visão dos patrões se fundamenta numa relação entre eles, através de uma estratégia racionalizada, para garantir renda. Este benefício financeiro se fundamenta na troca, na qual se espera do outro o cumprimento moral da palavra, como menciona o Patrão Porcino Neto:

O que vai muito é pela questão do foco, da determinação da gente em fazer um evento bacana, fazer um evento que agregue valor para a cidade. E também vai muito da palavra, do compromisso. Se eu vou para a vaquejada de um amigo meu em Assú ou em Campo Grande, então ele tem que pagar a visita aqui a mim. Então envolve muito trabalho, muito foco, muita determinação e muita participação nos eventos ao longo do ano, para a gente poder formar uma vaquejada dessa magnitude [...] Isso aí dura o ano inteiro, a vida inteira! (NETO, 2017)

O discurso do patrão Porcino Neto caracteriza a relação estabelecida entre patrão e vaqueiro, especialmente, profissional, que denomino de relações cruzadas, baseada no "contrato terceirizado". Nesse contexto, tal prática se constitui, sobretudo, por patrões, donos de parque ou aqueles que possuem algum produto, que vendem na vaquejada (insumos, medicamentos, estruturas para festas, etc.) e enviam toda semana vaqueiros para competirem nos outros eventos, que realizam competições simultâneas, em vários locais do Brasil. A estratégia do patrão e do vaqueiro é garantir sua presença nas competições, para outros vaqueiros e patrões, a fim de ser retribuído no futuro. Ao prestigiar a competição de outro patrão e do seu vaqueiro, a retribuição é sempre esperada pelo patrão e seu vaqueiro.

Neste contexto, as relações de amizades são cultivadas entre os vaqueiros e patrões, como estratégia discursiva, para não fechar as porteiras do intercâmbio da troca, considerando que ambos tendem sempre a necessitar do outro para realizar suas atividades na vaquejada, como negociar cavalos, conseguir competidores e bois para a sua competição ou treino, dentre outras 
necessidades. Isso significa que os vaqueiros e patrões necessitam de parcerias, nas quais um possa ajudar o outro. Por isso, é comum os vaqueiros dizerem que na "vaquejada todo mundo é amigo" ou que "todo mundo conhece todo mundo". Isso significa que um amigo tem palavra e tem atitude de sempre retribuir um "favor" feito por outro vaqueiro e/ou patrão, funcionando como uma espécie de troca. Dessa forma, a troca se associa ao sacrifício econômico, assim como, na troca de valores.

O desejo de alguém por um objeto é satisfeito pelo sacrifício de um outro objeto, que é o foco do desejo de outrem. Tal troca de sacrifícios é o que constitui a vida econômica, e a economia, como forma social específica, "consiste não apenas em trocar valores, mas na troca de valores" (SIMMEL,1907, p. 80).

A troca de sacrifícios decorre do contrato, geralmente informal, que garante a participação nos eventos de vaquejada, baseado na palavra entre patrões e vaqueiros. Quando o patrão se "doa" financeiramente, enviando vaqueiros às vaquejadas dos seus pares, e é retribuído com a visita no seu evento, daquele que ele prestigiou, mantém um forte vínculo, para continuar estabelecendo amizade e negócio entre eles. Por outro lado, quando não há o compromisso de retribuição à sua visita na vaquejada de outro patrão, pode gerar desprestígio e dependendo da situação, inimizade, pelo tal ato de desrespeito e de desonra. Sabendo disso, os patrões procuram evitar tal atitude, tendo em vista que, ao enviar representações às vaquejadas dos seus pares lhes garantem, além de retorno financeiro, poder e prestígio social na comunidade da vaqueirama e nas sociedades em que se realizam os eventos.

Os vaqueiros profissionais também estabelecem outros tipos de relações contratuais com o patrão, que são mais duradouras do que a relação cruzada, uma vez que esta relação não é imediatista, no sentido de competir apenas em uma vaquejada. Nesta modalidade contratual, o vaqueiro profissional já tem certo o seu local e sua equipe de trabalho, na qual vai competir. Honestidade e confiança são utilizadas como atributo discursivo para garantir as relações de trabalho informais com a maioria dos vaqueiros profissionais, durante o processo das vaquejadas, demonstrando que entre patrões e vaqueiros, o uso da palavra é o mecanismo mais importante, para selar uma relação duradoura, como destaca os personagens da vaquejada. Os vaqueiros profissionais e os patrões que mantém uma relação mais duradoura, através do contrato, retrataram que a maior parte dele é realizada de forma informal, conforme os vaqueiros Carlinhos Timóteo, Renato Tobias e os patrões José Everaldo e João Alves responderam, respectivamente: "O acordo do contrato é feito de modo labial mesmo, não existe a carteira assinada" (TIMÓTEO, 2015); "É um salário e a metade do prêmio. É contrato oral”; (TOBIAS, 2017); "Lá não tem esse negócio de contrato. Eu pago salário." (EVERALDO, 2016); “Ele (vaqueiro) é como se fosse uma pessoa de casa, da minha família, eu gosto dele e ele gosta da gente, é amigo dos meus filhos.” (ALVES, 2016). 
Embora apareça no âmbito discursivo as relações de afetividade, honestidade e confiança, do ponto de vista formal, nas relações de trabalho entre patrões e vaqueiros na vaquejada há a questão da perda de direitos de trabalho, como o seguro-desemprego, auxíliodoença, aposentadoria, dentre outros, o que pode deixar os vaqueiros sob a dependência ainda mais forte do patrão. Este controle do patrão reproduz na vaquejada-espetáculo a mentalidade agrária do passado do poder de mando aristocrático na nossa sociedade, que eram praticados ainda na época da pega do boi no mato, como enfatizara Cascudo $(1984$, p. 32) que "o vaqueiro devia prestar contas ao patrão, muito mais em base de honestidade e do seu crédito pessoal moral, do que na exibição da possível documentação e comprovação comprobatória”.

Ao tentar compreender como se estabelecia especificamente as relações entre patrões e vaqueiros, foi perguntado aos vaqueiros amadores como faz para obter um patrão? Assim, o discurso do vaqueiro amador Ailson Junior destacou que: "precisa ter responsabilidade, ter respeito, pra mim primeiro isso e o segundo um bom desempenho na pista de vaquejada" (JUNIOR, 2017). Os vaqueiros profissionais responderam na mesma lógica dos vaqueiros amadores, conforme, respectivamente, as falas de Kaká e Celso Vitório: e "tem que ter responsabilidade, ser honesto primeiramente, saber cuidar dos animais, ser um bom vaqueiro também” (KAKÁ, 2015); “ter responsabilidade e cuidar das coisas do patrão" (VITÓRIO, 2017).

Os discursos apresentam como fator fundamental, para estabelecer uma relação duradoura com o outro, o valor moral do respeito, da honestidade, da responsabilidade e do saber cuidar dos animais para, em seguida, elencar a conquista de prêmios.

Outro ponto que é importante ressaltar é a ênfase dada às "recompensas". Ganhar prêmios é importante, mas cuidar do "tesouro do patrão" se torna ainda mais relevante, na medida em que, os caminhões, os cavalos e as propriedades são valorativas e significativas do seu dono. A responsabilidade com os bens do patrão na vaquejada, como negócio e como um patrimônio, devem ser bem cuidados, para não haver prejuízos na conquista de prêmios ou na destituição do que fora conquistado nas vaquejadas. Nesse sentido, a ideia do patrimonialismo é uma forma de dominação tradicional, baseada na responsabilidade dos bens do seu provedor e no comportamento moral adequado nas vaquejadas. A dominação se materializa na maneira como o vaqueiro deve conduzir o cavalo, o caminhão, os alimentos, o cheque para pagar as contas. Em tudo que tem a tutela do patrão, configura-se uma "espécie de força" marcada nos objetos dele e na mentalidade do vaqueiro, como uma obrigação a ser seguida. Dessa forma, essa reprodução se revela pelo "poder simbólico que é, com efeito, esse poder invisível, o qual só pode ser exercido com a cumplicidade daqueles que não querem saber que lhe estão sujeitos ou mesmo que o exercem" (BOURDIEU, 1989, p. 7).

O patrão, para tutelar um vaqueiro como seu representante, usa a confiança e o desempenho para saber se, de fato, o contratante poderá corresponder as suas expectativas. Quanto mais conceituado (patrão e vaqueiro campeão, homens de palavra) for quem o indicou e seu desempenho for positivo, mais lhe será garantido uma contratação para competir. Deste 
modo, a indicação positiva de outro vaqueiro ou de outro patrão respeitado na vaquejada promove a contratação do vaqueiro. Por isso, é muito comum na vaquejada um vaqueiro ser indicado por outro vaqueiro ou por outro patrão, a fim de lhe conferir um novo contrato, conforme discurso do vaqueiro profissional Alexandro Suassuna:

Rapaz eu comecei lá na região, ia treinar num canto, e o professor da escola ia treinar e ele me chamava e eu ia com ele treinando e depois fui indo e comprei um cavalinho de direita, e eu só corria de direita. Ai depois foi uns meninos correr para Ronaldo, lá de Catolé e outros pra o povo de Juvenal, que eram uns cabas mais antigos que corriam em vaquejada e que eram patrões, ai eu comecei a andar com eles e a correr de esquerda. Aí comecei ganhando já as primeiras competições correndo de esquerda no interior. Aí um dia o finado Tête viu eu correndo, e disse aqui a Fábio Porcino. Aí meu primeiro patrão de corrida grande foi os Porcino, e eu corri três anos seguidos pra eles! E foi onde tudo começou (SUASSUNA, 2017).

De um lado, a indicação fomenta mais segurança ao patrão, para decidir sobre a contratação do vaqueiro. Por outro lado, a indicação do vaqueiro lhe confere mais responsabilidade, em defender seu patrão nas vaquejadas, bem como, zelar pelo nome de quem o indicou. Dessa forma, os qualificativos que ingressaram o vaqueiro naquela equipe de vaquejada implica buscar corresponder ao que foi esperado durante sua contratação. Quando isso não ocorre, o patrão pode trocar de vaqueiro. No entanto, quando o vaqueiro atende positivamente ao que se espera dele, sendo responsável e campeão, ele poderá deixar seu patrão, não por frustração de não atender ao que se espera, mas por propostas mais tentadoras de outros patrões. O cenário vitorioso possibilita ao vaqueiro capital simbólico para escolher qual patrão poderá representar. Vê-se na vaquejada que determinados patrões convidam vaqueiros, para lhes representar nas vaquejadas, mas o vaqueiro só aceita se o mesmo comprar, junto com ele, os cavalos que ele compete contratar seu tratador de cavalos e aumentar seu salário. Assim, se percebe que "o valor jamais é uma propriedade inerente aos objetos, mas um julgamento que os sujeitos fazem sobre eles. "Essa subjetividade é apenas provisória e, com efeito, não muito essencial" (SIMMEL,1907, p. 63). Dessa forma, a relação entre patrão e vaqueiros se correlaciona ao julgamento que as pessoas fazem das coisas e não ao valor das coisas em si. As coisas assumem valor, à medida em que os indivíduos em suas relações sociais atribuem sentido a elas, configurando uma dimensão social.

Essa concepção foi percebida quando foi feito o questionamento aos vaqueiros amadores, vaqueiros profissionais e aos patrões sobre: O que faz o vaqueiro trocar de patrão e vice-versa? Os discursos, respectivos, do vaqueiro amador Thales Araújo, do vaqueiro profissional Kaka e do patrão Ornilson Buarque, compartilham de premissas semelhantes, a saber: “Todo mundo quer as suas melhoras, né? Se você está em um negócio, e acha que pode crescer, então você muda" (ARAUJO, 2017); "Não ganhar prêmios. Cavalo. Irresponsabilidade” (KAKÁ, 2015); “Tem que ter uma boa amizade, tem que ser responsável, porque hoje não é brincadeira; você ter um patrão e ele lhe entregar um cavalo bom, um caminhão (BUARQUE, 2017). 
Além da responsabilidade, destacam a condição de trabalho e o desempenho para ser campeão. Para garantir isso, é preciso que os vaqueiros amadores e vaqueiros profissionais tenham condição financeira, para bancar uma equipe de vaquejada qualificada. Enquanto o vaqueiro profissional deve ter ao seu lado um "patrão forte", o vaqueiro amador em si já é "forte" para se autofinanciar. Se o vaqueiro deve possuir habilidade e responsabilidade, o patrão deve garantir, além do caminhão, suprimentos e vaqueiros, cavalos competitivos.

\section{Considerações finais}

Como explicitamos no início do presente texto, a pesquisa realizada procura compreender o negócio, a festa e cultura na vaquejada-espetáculo, ressaltando, simultaneamente, a relação dialética da cultura, apropriada pelo consumo e do consumo apropriado pela cultura, construindo dinâmicas sociais diversas nas relações estabelecidas entre patrões, vaqueiros e frequentadores do evento. Neste contexto, a mentalidade patronal ritualizada constantemente nas vaquejadas (competições e festas) revelam o poder de mando de uma elite que ocupa os espaços não apenas deste evento, mas da sociedade, como ocorrem em todos os circuitos do evento no Brasil.

Também há de se destacar que a vaquejada-espetáculo, a festa e a expressão cultural, transcendem as raias da competição econômica para vislumbrar os efeitos sociais do ser campeão de vaquejada, do ser que quer disputar e concorrer com alguém. Essa prática é comum no contexto da sociedade monitorada por relações capitalistas que se tornam relações de uma tradição cultural arraigada na mentalidade rural, que ainda pendura no universo da urbanidade, conforme configurada no imaginário dos seus diferentes personagens, como o playboy fazendeiro e o boy vaqueiro.

\section{Referências}

ADORNO, Theodor W; HORKHEIMER, Max. Dialética do esclarecimento. Fragmentos Filosóficos.1947. Disponível em: http://antivalor.vilabol.uol.com.br. Acesso em: 06 de jun. 2015.

AIRES, Francisco Janio Filgueira. O espetáculo do cabra-macho: um estudo sobre os vaqueiros nas vaquejadas no Rio Grande do Norte. 2008. 183 f. Dissertação (Mestrado em Antropologia Social) - Programa de Pós-Graduação em Antropologia Social, Universidade Federal do Rio Grande do Norte, Natal.

BARBOSA, Eriosvaldo Lima. Valeu boi! O negócio da vaquejada. Teresina: EDUFPI, 2006.

BOURDIEU, Pierre. Razões Práticas: sobre a teoria da ação. Campinas: Papirus, 1996.

. A economia das trocas simbólicas. São Paulo: Perspectiva, 2011.

_. O poder simbólico. Lisboa: Difel, 1989.

CARVALHO, José Jorge. Espetacularização e Canibalização das Culturas Populares. Revista Anthropológicas, Recife, v. 21, n. 1, p. 29-76, 2010.

CASCUDO, Luís da Câmara. História do Rio Grande do Norte. Rio de Janeiro: Edições Achimaé, 1984.

CECCHETTO, Fátima Regina. Violências e estilos de masculinidades. Rio de Janeiro: Editora FGV, 2004

CLIFFORD, James. Sobre a autoridade etnográfica. In: Gonçalves, REGINALDO, José. (Org.). A experiência etnográfica: antropologia e literatura no século XX. Rio de Janeiro: Editora UFRJ, 1998. p.17-62. 
DAMATTA, Roberto. A casa e a rua: espaço, cidadania, mulher e morte no Brasil. São Paulo: Brasiliense, 1997. DEBORD, Guy. A sociedade do espetáculo. Rio de Janeiro: Contraponto, 1997.

FORRÓ, Solteirões do. Vou pra Vaquejada. Brasil: A3 Entretenimento, c. 2017. In: Vagalume. Disponível em: https://www.vagalume.com.br/solteiroes-do-forro/vou-pra-vaquejada.html. Acesso em: 20 out. 2017.

PEGAÇÃO, Pedrinho. Estilo Capa Louca. Brasil: Pedrinho Pegação c.2016. In: Letras. Disponível em: https://www.letras.mus.br/pedrinho-pegacao/capa-louca/. Acesso em: 22 nov. 2017. MAGNANI, José Guilherme Cantor. Etnografia como prática e experiência. Horizontes antropológicos, Porto Alegre, v. 15, n. 32, Dec. 2009.

SIMMEL, Georg. Philosophie des Geldes. Frankfurt: Suhrkamp, 1907.

SILVA, Gilnara Karla Nicolau da. O espaço do consumo e o consumo do espaço no município de Macaíba-RN a partir das festas de vaquejadas (1980-2012). 2013. 171 f. Dissertação (Mestrado em Geografia) - Programa de Pós-graduação e Pesquisa em Geografia, Universidade Federal do Rio Grande do Norte, Natal.

SOUZA, Jessé. Ralé brasileira: quem é e como vive. Belo Horizonte: Editora UFMG, 2009.

WALTER, Mano. Balada do Vaqueiro. Brasil: Universal Music International Ltda. c.2016. In: Letras. Disponível em: https://www.letras.mus.br/mano-walter/balada-do-vaqueiro/ Acesso em: 20 out. 2017.

Playboy Fazendeiro. Brasil: Universal Music International Ltda. c.2016. In: Letras. Disponível em: https:// www.letras.mus.br/mano-walter/play-boy-fazendeiro/.20/10/2017 Acesso em: 20 out. 2017

ZUMTHOR, Paul. Introdução à poesia oral. Belo Horizonte: Editora UFMG, 2010.

Recebido em: 10/07/2018

Aceito em: 04/10/2018 